Scientiæ studia, São Paulo, v. 12, n. 4, p. 751-66, 2014

\title{
îst \\ Sobre os obstáculos sociais ao desenvolvimento histórico da razão
}

\author{
Sylvia Gemignani Garcia
}

\begin{abstract}
茴
RESUMO

O artigo inicia-se com uma descrição da problemática moderna, tal como formulada pela sociologia do século XIX, em torno dos limites e possibilidades da razão científica. Explicita-se, assim, a questão da dualidade entre o conhecimento instrumental, para o controle técnico do mundo, e o conhecimento reflexivo, que abarca as várias dimensões de sentido das práticas humanas. Em seguida, o artigo expõe, como exemplares das explicações propostas pelas perspectivas reflexivas para o amplo predomínio contemporâneo do conhecimento instrumental, primeiro, o modelo da interação entre valores e atividade científica de Hugh Lacey e, segundo, a sociologia das condições sociais do desenvolvimento dos campos científicos de Pierre Bourdieu. Ao colocar lado a lado um trabalho filosófico de articulação entre a epistemologia e a ética e uma teoria sociológica sobre as condições sociais do desenvolvimento histórico da razão, o artigo retém balizas fundamentais para a exploração das possibilidades das perspectivas histórico-racionalistas que buscam escapar da alternativa dualista entre o racionalismo ortodoxo e o relativismo. Ambas análises exploram possibilidades abertas por perspectivas transversais que buscam elucidar as relações entre diferentes esferas de atividades sem recusar-lhes suas especificidades, delineando problemas a serem investigados de modo a fazer avançar a reflexividade, junto com o conhecimento empírico dos processos históricos de reprodução da organização social e dos valores culturais dominantes.
\end{abstract}

Palavras-Ghave $\bullet$ Sociedade moderna. Conhecimento instrumental. Conhecimento reflexivo. Práticas científicas. Estratégias de pesquisa. Campo científico. Lacey. Bourdieu.

\section{UMA PROBLEMÁTICA MODERNA}

O papel da racionalidade científica na constituição das sociedades complexas modernas foi abordado pela sociologia clássica no alvorecer da sociedade industrial na Europa do século xix. De diferentes formas, a partir de perspectivas teórico-metodológicas diversas, os autores posteriormente consagrados como os fundadores do pensamento sociológico apontaram os limites da racionalidade cognitivo-instrumental da ciência moderna em relação às dimensões simbólicas da experiência humana, aos valores culturais, políticos, morais e éticos que expressam as representações acerca dos sentidos e significados do mundo. 
Exemplar desse diagnóstico é a visão de Max Weber (1970), da ciência e da técnica científica como a vanguarda do longo processo histórico de intelectualização, pelo qual se retira toda magia da relação humana com o mundo. Ampliando sem cessar os domínios sobre os quais a aplicação da racionalidade instrumental permite o controle técnico do mundo, a ciência opera neutralizando moralmente os fenômenos para construí-los como objetos de investigação. Mas a contrapartida disso é que ela nada tem a dizer acerca dos sentidos, incluindo os pressupostos de valor que orientam suas próprias práticas, que ficam, assim, fora do âmbito de seu entendimento: "a ciência pressupõe que o resultado de seu trabalho é importante em si, isto é, merece ser conhecido. Ora, (...) esse pressuposto escapa a qualquer demonstração por meios científicos" (Weber, 1970 [1919], p. 36).

Em um exemplo de singular significação para a experiência contemporânea, Weber cita "uma tecnologia altamente desenvolvida do ponto de vista científico, tal como é a medicina moderna": seguindo o pressuposto geral de que o dever do médico é o de

conservar a vida pura e simplesmente (...), o médico mantém vivo o moribundo, mesmo que este lhe implore pôr fim a seus dias e ainda que os parentes desejem e devam desejar a morte, conscientemente ou não, porque já não tem mais valor aquela vida, porque os sofrimentos cessariam ou porque os gastos para conservar aquela vida inútil - trata-se, talvez, de um pobre demente - se fazem pesadíssimos. (...) A medicina, contudo, não se propõe a questão de saber se aquela vida merece ser vivida e em que condições. Todas as ciências da natureza nos dão uma resposta à pergunta: que deveremos fazer, se quisermos ser tecnicamente senhores da vida. Quanto a indagações como "isso tem, no fundo e afinal de contas, algum sentido", "devemos e queremos ser tecnicamente senhores da vida?" aquelas ciências nos deixam em suspenso ou aceitam pressupostos, em função do fim que perseguem (Weber, 1970 [1919], p. 37).

Na perspectiva crítica de Karl Marx a limitação está vinculada à concepção dicotômica que impede que as práticas humanas possam ser objetivamente consideradas:

O principal defeito de todo materialismo até aqui é que as coisas, a realidade e a sensibilidade são concebidas apenas sob a forma de objetos ou de intuição, não como atividade prática humana sensível, como práxis, não subjetivamente. Por isso, em oposição ao materialismo, o aspecto ativo foi desenvolvido pelo idealismo apenas abstratamente, porque, como é claro, ele não conhece a atividade humana sensível e real como tal. Feuerbach quer conceber os objetos sensíveis como 
realmente distintos dos objetos do pensamento, mas ele não concebe a atividade humana como atividade objetiva (Marx \& Engels, 1970, p. 117-8).

Pode-se identificar aqui uma problemática constitutiva da experiência moderna, formulada de diversos modos pelos observadores da sociedade industrial que apontam os descompassos entre o avanço do domínio técnico e o recuo ético, entre a velocidade do desenvolvimento da cultura objetiva, para falar com Simmel (2005), e a estagnação da dimensão moral, fonte do estado de anomia social, segundo Durkheim $(2004)$.

Isso é suficiente para situar a perspicácia dos sociólogos clássicos para abordar o desenvolvimento histórico da ciência em suas ligações contraditórias com a experiência social da modernidade secular, racional e igualitária, apontando e criticando, em graus variados, a racionalização unilateral promovida pela visão dicotômica de objetividade e subjetividade que abre amplo espaço para o conhecimento de tipo instrumental enquanto cria obstáculos para o conhecimento de caráter reflexivo.

Apesar disso, estabeleceu-se, posteriormente, uma visão segundo a qual a sociologia clássica não havia tomado a ciência e a técnica como temas de um verdadeiro programa de pesquisa, de modo que somente com Robert Merton essa subárea teria se instituído (cf. Barnes, 1980, p. 12). Esse relato é expressivo do impacto da sociologia norte-americana da primeira metade do século xx na configuração do caráter científico da disciplina que conquista legitimidade como conhecimento objetivo na medida em que abandona, como problemas que não podem ser construídos como objetos de pesquisa, as questões formuladas do ponto de vista da análise crítica da produção de conhecimento racional e suas ligações e implicações sociais.

Em múltiplas áreas temáticas, como, notadamente, nos estudos sobre religião e culturas de outros povos, as ciências sociais construíram abordagens e instrumentos potentes para a análise dos condicionantes sociais das representações e das atividades humanas, deixando, entretanto, resguardados dessas abordagens os produtos do pensamento racional. Apesar da contribuição da perspectiva mertoniana de análise da ciência como uma instituição social com um éthos específico, essa perspectiva sociológica não abarca os conteúdos do conhecimento, a serem devidamente abordados em sua lógica e consistência interna pela epistemologia (cf. Marcovitch \& Shinn, 2013).

O cenário começa a transformar-se na segunda metade do século, em conexão com as repercussões de acontecimentos que alçam a questão dos usos sociais da ciência a novo patamar. O debate em torno das consequências culturais, políticas e éticas das aplicações científicas passa a abarcar o questionamento dos fundamentos da visão científica dominante, atravessando, assim, a rígida distinção entre fatores externos e aspectos internos do conhecimento. 
Em termos gerais, no âmbito dos estudos filosóficos, históricos e sociológicos da ciência, sob a ampla influência da obra de Thomas Kuhn, a dualidade entre a lógica imanente à razão e a organização social da atividade científica é posta em questão. Enquanto certas vertentes das ciências sociais voltam-se para a investigação dos modos pelos quais a estrutura do pensamento racional deriva da organização social no interior da qual ele se desenvolve, difundem-se as abordagens filosóficas que incorporam a consideração dos fatores históricos e sociais na caracterização dos procedimentos e produtos da atividade científica.

Mas desse quadro também emergem as posições de orientação relativista que, sob o diagnóstico da emergência da pós-modernidade, recusam a especificidade da ciência e apontam o esvanecimento das fronteiras entre esferas de atividades com legalidades próprias, características da diferenciação interna das sociedades modernas. Em sua configuração geral, o ponto de vista relativista passa a constituir uma nova forma de dualidade dicotômica, tendo no outro polo a visão tradicional da racionalidade cognitivo-instrumental. A dualidade oculta a afinidade entre as duas posições aparentemente opostas, limitando as possibilidades de conhecimento, de um lado, à "view from nowhere" da convicção objetivista não objetivada, e, de outro, à "view from everywhere" da desconstrução pós-moderna que ignora as condições sociais de produção do olhar desconstrutor (cf. Bourdieu, 2007, p. 130). Trata-se, então, de uma atualização da polaridade entre objetividade e subjetividade característica da modernidade, que repõe os obstáculos ao desenvolvimento do pensamento reflexivo, ao mesmo tempo que fortalece o predomínio da razão instrumental, aprofundando a discrepância moderna entre a velocidade do avanço técnico e o subdesenvolvimento ético.

De fato, a movimentação no interior dos campos de estudos da ciência é correlata das revoluções tecnológicas que transformaram, notadamente a partir da segunda metade do século xx, o modo de produção de bens materiais e simbólicos e a divisão social do trabalho. A automação da produção e a reestruturação da esfera produtiva reorganizam o mercado de trabalho, transformando ideias constitutivas da sociedade moderna capitalista, tais como as noções de trabalho e de formação e trajetória profissionais, como constitutivas das identidades sociais. A proeminência de setores de atividades econômicas intensamente baseados em conhecimento promoveu os diagnósticos da passagem para uma fase pós-industrial da economia capitalista, alicerçada sobre bens imateriais - informação e conhecimento - e reorganizando o sistema de produção e o mercado de trabalho em torno dos chamados "trabalhadores simbólicos" (cf. Reich, 1994). De "sociedade do conhecimento" (Bohme \& Stehr, 1986) à "economia do aprendizado" (Lundvall, 1996), multiplicam-se as interpretações das mudanças contemporâneas, com impactos profundos para a forma de pensar a produção de conhecimento e a formação de produtores de conhecimento e de profissionais qualificados para uma 
economia mundial e um mundo do trabalho definidos por crescente complexidade e incerteza. Na dimensão cultural, as novas tecnologias têm impactos extraordinários nos ideais e nas práticas, no presente e nas imagens do futuro, na medida em que são intensamente difundidas previsões de caráter revolucionário ímpar, acenando, por exemplo, com a possibilidade futura de conquista da saúde plena e até mesmo da imortalidade (cf. Le Breton, 2008).

As pressões advindas da economia e das tendências culturais expressam-se no interior do debate sobre a produção da ciência. Particularmente na última década do século passado, os chamados modelos pós-modernos de produção e difusão do conhecimento afirmam o advento de uma nova era para a ciência e suas aplicações. Rompendo com seu isolamento social e seus pressupostos epistemológicos de suspensão dos interesses práticos, as instituições e as práticas tecnocientíficas estariam passando por uma revolução determinada pela consciência social de sua importância econômica na competição global contemporânea. Descrito como um processo inexorável, uma ciência comercialmente orientada serve de base para a proposição de políticas científicas, educacionais e acadêmicas reconfiguradas em torno de uma finalidade central, a produção de inovações de produtos e processos (cf. Gibbons et al., 1999; Etzkowitz \& Leydesdorff, 2000; Etzkowitz, 2000).

Mas essas novas interpretações das relações entre ciência e sociedade são, como já indicado acima, marcadamente controversas. O processo histórico de desenvolvimento da ciência e suas técnicas desde a Segunda Guerra Mundial - isto é, desde o desenvolvimento da bomba nuclear - e, notadamente, nas últimas décadas do século passado - com o agravamento, por exemplo, do problema ambiental - reatualiza o debate crítico sobre os sentidos do progresso científico e tecnológico, questionando o modelo de desenvolvimento característico da modernidade. Em certo sentido, portanto, a passagem para o século xxi se assemelha ao final do século xIx, quando a consolidação da sociedade industrial promoveu o questionamento do significado da civilização moderna.

\section{LAGEY E O MODELO DAS INTERAÇÕES ENTRE \\ AS ATIVIDADES GIENTÍFICAS E OS VALORES}

Considerando esse cenário amplo, interessa aqui situar a posição racionalista que busca superar a formulação dicotômica, em suas variadas versões, avançando no sentido do entendimento dos limites e possibilidades da razão científica. Nesse registro, no campo da filosofia da ciência, o modelo da interação entre as atividades científicas e os valores (M-CV) de Hugh Lacey é exemplar. 
A reflexão de Lacey sobre o papel dos valores na ciência, entendida como uma atividade social e histórica, parte da análise da concepção tradicional da ciência moderna, historicamente incorporada nas instituições contemporâneas de produção de conhecimento e formação de cientistas, revelando o papel de um conjunto de valores que são incorporados pelos cientistas e que fornecem as direções dominantes de pesquisa. A tensão fundamental visada, no que concerne à racionalidade, refere-se à metafísica materialista subjacente à concepção da ciência moderna que projeta, a partir de metodologias originalmente desenvolvidas em um contexto histórico de enfrentamento de concepções transcendentais do mundo, um modelo da racionalidade em geral e uma visão correlata da realidade do mundo interligadas entre si (cf. Lacey, 2009, p. 683-4). A clara predominância da razão instrumental, patente nos grandes projetos da big science, que se traduz na escala do M-CV pelo predomínio das estratégias descontextualizadoras e sua ligação com o valor do controle, faz que as investigações científicas se concentrem, então, nos padrões de organização e funcionamento dos fenômenos em termos de suas estruturas, processos, interações e leis subjacentes (EPILs), tais como eles funcionam sem qualquer influência da ação humana, tornando inteligível "o mundo como ele realmente é", abstraído de todos os contextos sócio-históricos da experiência humana do mundo (2009). Essas estratégias, por isso designadas descontextualizadoras (ED) (cf. Lacey \& Mariconda, 2014; Lacey, 2014), baseiam-se, assim, em uma ideia de objetividade ou imparcialidade que se define abstraindo tudo o que se refere ao humano, às intenções, disposições, interesses e valores que projetam significados à natureza e à sociedade, enquanto expressões subjetivas parciais, racionalmente ininteligíveis.

Ao subtrair toda dimensão de sentido da razão científica, limitando a racionalidade ao controle técnico do mundo, as EDs não podem constituir como objeto de investigação seus próprios pressupostos, bem como os sentidos humanos dos usos sociais dos resultados de suas pesquisas, atuando desse modo contra a expansão dos domínios de fenômenos a serem abarcados pela reflexão de natureza racional, fortalecendo a unilateridade do desenvolvimento histórico da razão e enfraquecendo o ideal científico da abrangência (cf. Lacey \& Mariconda, 2014).

$\mathrm{Na}$ direção da ampliação desses limites do modelo tradicional, sintetizado na máxima de que "a ciência é livre de valores", o M-CV distingue entre valores cognitivos e valores éticos e sociais, buscando esclarecer os papéis legítimos desempenhados pelos valores éticos e sociais nas diferentes etapas em que se desenrola a pesquisa científica. O fundamental aqui é a formulação das relações de reforço mútuo entre os valores éticos e sociais e a adoção de estratégias de pesquisa, definida como a primeira etapa na sistematização proposta das atividades de pesquisa, abarcando desse modo os 
pressupostos das estratégias de pesquisa que as EDs deixam fora de seu domínio de investigação (cf. Lacey, 2008a; 2010).

Revela-se assim o paradoxo que caracteriza a visão dominante das EDs que, conforme suas próprias definições, não têm como sustentar racionalmente seus próprios pressupostos. Mas são esses pressupostos - e não os resultados de pesquisa - que implicam a desqualificação, como irracionais, de outras definições de racionalidade e visões de mundo e, possivelmente, de outras estratégias de pesquisa que busquem construir seus objetos abarcando o entrelaçamento entre racionalidade e intencionalidade das práticas humanas, ou seja, aquelas classes de fenômenos dos quais as EDs não tratam e, por isso, supõem que não existam ou que não podem ser racionalmente investigados (cf. Lacey, 2009).

Dentro de seus limites, a adoção das EDs produziu e continua produzindo conhecimento sobre grande variedade de fenômenos com enorme potencialidade de gerar aplicações tecnológicas com impacto profundo e crescente na sociedade e na cultura. Trata-se aqui da especificação do papel dos valores éticos e sociais na última etapa apontada pelo M-CV para as atividades científicas; etapa referente à aplicação da ciência. A grande eficácia das aplicações dos resultados da pesquisa feita sob as EDs para o controle técnico do mundo - e que caracteriza, ao mesmo tempo, o extraordinário êxito da ciência moderna - reforça o valor do controle instrumental. As EDs mostram-se particularmente eficientes no desenvolvimento de inovações tecnológicas, mantendo assim relações de reforço mútuo com a perspectiva de valores do progresso tecnológico $\{\mathrm{VPT}\}$ (cf. Lacey, 2008b; Lacey \& Mariconda, 2014). O sucesso das aplicações tecnocientíficas pode aparecer assim como justificativa da legitimidade das práticas científicas que as tornam possíveis, sem que seja preciso considerar cuidadosamente as consequências e implicações dessas aplicações.

Assim, outro ponto crítico relativo às limitações da pesquisa realizada sob as EDs refere-se aos problemas envolvidos na aplicação do conhecimento científico, quinta e última etapa da sistematização das atividades científicas proposta pelo M-CV. As pesquisas formuladas a partir de metodologias descontextualizadoras sobre os riscos envolvidos na adoção de inovações tecnológicas limita-se a objetos constituídos pelos mecanismos físicos, químicos e biológicos de produtos e aplicações, e não alcança os efeitos e impactos das aplicações nas dimensões da experiência humana, necessariamente inserida em contextos sociais específicos (cf. Lacey \& Mariconda, 2014). Contudo, a quase exclusividade das EDs no sistema institucional da ciência oculta e inibe o desenvolvimento de metodologias alternativas, formuladas a partir de estratégias contextualizadas (EC), sensíveis ao contexto, capazes de formular objetos que incorporam as dimensões da experiência humana e mais adequadas, portanto, a promover 
uma investigação racional sobre os efeitos das aplicações técnicas do conhecimento científico, concebendo os riscos da introdução de inovações em sentido mais abrangente. A agroecologia é intensamente analisada por Lacey como exemplar da existência e viabilidade de estratégias de pesquisa desse tipo, que, no entanto, restam como pequenos nichos de trabalho no interior de umas poucas instituições de pesquisa, quase invisíveis em comparação com o volume de recursos e de políticas de incentivo às numerosas e dominantes linhas de pesquisa baseadas nas EDs, no caso em questão, as pesquisas para o desenvolvimento de sementes transgênicas (cf. Lacey, 2006, 2008b, 2014; Mariconda, 2014).

É nesse quadro que se desenvolve a argumentação de Lacey em defesa do incentivo à diversificação das estratégias de pesquisa no interior das instituições científicas. Com a abertura de espaço institucional ao desenvolvimento de alternativas ao conhecimento instrumental em uma política para a pesquisa multiestratégica fortalece-se o ideal científico da abrangência dos domínios de fenômenos investigados racionalmente, na produção de conhecimentos relevantes para o entendimento das mudanças sociais produzidas pelas aplicações tecnológicas e, portanto, para o desenvolvimento de um controle racional desses efeitos e consequências. Além disso, a pluralidade de estratégias liga-se à ampliação do espectro de valores sociais e éticos reconhecidos como legítimos no âmbito das práticas e políticas científicas, especificamente, os valores da justiça social, democracia participativa e sustentabilidade \{VJsDPs\}, de modo que a contribuição da pesquisa multiestratégica para a ampliação da racionalidade científica implica avanços correlatos no aprofundamento do caráter democrático da organização social e política das sociedades contemporâneas (cf. Lacey \& Mariconda, 2014; Lacey, 2014).

É somente pela identificação das articulações entre a atividade científica e os valores sociais que se pode entender a condição de quase exclusividade mantida pelas EDs ao longo de toda a história da ciência moderna, inibindo o desenvolvimento de estratégias alternativas racionalmente viáveis e possibilitando as alegações de sua legitimidade a partir da eficácia de suas aplicações para o controle técnico do mundo. Nesse registro são pontos fundamentais da argumentação de Lacey a distinção entre eficácia e legitimidade, que pode ser claramente visualizada na figura 1 do artigo de Lacey e Mariconda (2014, p. 649) deste número, e entre justificação e endossamento (cf. Lacey, no prelo; Sacrini, 2014).

São, portanto, razões sociológicas que podem tornar inteligível o predomínio de uma concepção de racionalidade científica cujos limites lógicos foram expostos de numerosas maneiras ao longo de mais dois séculos. A sistematização das atividades científicas de Lacey no M-CV oferece esclarecimentos precisos para a compreensão das dinâmicas de interação entre os valores sociais e as práticas científicas delineando cer- 
tas possibilidades de investigação promissoras em termos do avanço do diálogo entre a filosofia e a sociologia da ciência, para um entendimento mais profundo da produção social de obstáculos ao desenvolvimento da racionalidade humana e suas implicações para a realização dos valores democráticos de justiça, equidade e sustentabilidade dos modos de vida em confronto na época contemporânea.

\section{Bourdieu E A AUTONOMIA RELATIVA DA GIÊNGIA}

No campo sociológico, a obra de Pierre Bourdieu aborda as relações entre ciência e sociedade explorando aspectos das dimensões econômicas, sociais, culturais e políticas e mobilizando instrumentos e problemas elaborados pelas sociologias da ciência, da cultura, da educação, do trabalho e do conhecimento, visando o estudo dos padrões e processos modernos de socialização, pelos quais se produzem e reproduzem os modos de pensar, agir e sentir predominantes nas sociedades contemporâneas altamente diferenciadas (cf. Durkheim, 1972, 1995; Mauss, 2003; Bourdieu, 1974, 2005).

Com a proposta de uma teoria dos campos Bourdieu incorpora criticamente as contribuições de Marx, Durkheim e Weber visando um entendimento da ação prática nos termos de uma economia das trocas materiais e simbólicas que sustentam, na modernidade, as estruturas e as interações sociais. Trata-se, de saída, de buscar uma sociologia do conhecimento que seja capaz de superar a dicotomia entre a análise interna - que se concentra na pureza interna da totalidade da obra, incapaz de conceber a relação entre conhecimento e poder - e a análise externa das obras intelectuais - que subordina todo conhecimento ao campo do poder. De modo correlato, busca-se desenvolver um conhecimento de tipo praxiológico para além da oposição entre o modo de conhecimento objetivista e o modo fenomenológico, ambos igualmente distantes de uma teoria do conhecimento prático do mundo (cf. Bourdieu, 1983).

A noção de campo quer designar um universo intermediário que traduz em linguagem própria, com seus códigos próprios, os conflitos entre sentidos que expressam as relações de força, ou seja, as relações sociais de dominação de certos grupos por outros em um estado dado em certo tempo e lugar. O objetivo é escapar das duas abstrações polares do pensamento sociológico: por um lado, o subjetivismo dos enfoques individualistas da teoria da escolha racional ou do interacionismo simbólico e, por outro lado, os estruturalismos que despojam os agentes de toda capacidade criativa, tomando-os como suportes das estruturas, sejam elas simbólicas como no estruturalismo cultural de Lévi-Strauss, sejam elas estruturas sociais do modo de produção capitalista como em Althusser. 
Homologamente, no estudo das obras intelectuais, seus produtores e consumidores, nos microcosmos criados em diferentes domínios de atividades, Bourdieu quer superar a dicotomia que marca a história das sociologias da arte e da ciência, entre a leitura interna e a externa. Para o enfoque mertoniano da ciência, a sociologia trata exclusivamente das práticas institucionalizadas e nada tem a dizer sobre a consistência interna das obras, tarefa da epistemologia. Mas os críticos de Merton, de orientação construtivista, caem no equívoco oposto e explicam o conteúdo das obras como resultado de negociações contingentes entre diversos atores conectados em redes sociais nos processos e interações concretos da produção de conhecimento. A polaridade se duplica nas posições opostas quanto ao caráter diferenciacionista do conhecimento científico: totalmente autônomo para os primeiros; despojado de qualquer especificidade para os segundos.

O campo, tal como elaborado por Bourdieu, denomina uma instância que conquistou historicamente uma autonomia relativa, fruto da diferenciação do mundo social e dos modos de conhecimento do mundo: cada campo rege suas disputas internas por seus próprios critérios específicos, mas guarda homologias estruturais com as estruturas socioeconômicas das sociedades de classes, historicamente instituídas pelas revoluções burguesas que promoveram a substituição das linhagens hereditárias por qualificações escolares (capital cultural) nas disputas de poder no âmbito do Estado moderno. Assim, Bourdieu pretende construir um enfoque teórico-metodológico transversal, capaz de dar conta dos modos pelos quais se articulam as dimensões macro (estruturas e processos), média (instituições e grupos sociais) e micro (interações face a face entre indivíduos) das relações sociais (Shinn \& Ragouet, 2008; Shinn, 2008; Bourdieu, 1996).

Concebendo a razão como um produto histórico, esse enfoque permite investigar as condições de possibilidade do desenvolvimento histórico do pensamento racional, isto é, a constituição de campos de produção e difusão de conhecimentos e suas lutas internas em torno da definição das regras do jogo específico e das jogadas reconhecidas como verdadeiras e legítimas.

Como todo campo, o campo científico tem por princípio arbitrário um nomos que o constitui enquanto princípio de visão e divisão que define todas as questões pertinentes ao campo, com exceção daquelas capazes de questionar a lei que o constitui como tal, de modo que a matriz de tudo o que é pensável no campo mantenha-se impensada. A história do campo, das posições que o constituem e das disposições que favorece, é que permite esclarecer a crença pré-reflexiva no sentido e no valor de seus instrumentos e objetos. A socialização no interior de cada campo é o trabalho de reprodução desse habitus, a incorporação, entre os postulantes a entrarem no campo, de seu modo característico de ver e classificar que está na base dos investimentos de tem- 
po e energia dos agentes assim confinados aos móveis de interesse próprios de cada campo específico. "Cada campo é a institucionalização de um ponto de vista nas coisas e nos habitus" (Bourdieu, 2007, p. 121).

Mas diversamente dos outros campos, o campo científico caracteriza-se como um microcosmo de exceção, com sua potencialidade para gerar desvios que possibilitaram o desenvolvimento histórico da universalidade da razão. É pela abordagem histórica da razão que se pode encontrar "o princípio da independência relativa da razão perante a história" (Bourdieu, 2007, p. 132). São as regras do diálogo metódico e da crítica generalizada que constrangem os agentes que concorrem entre si por reconhecimento a utilizarem todos os recursos alcançados pelo campo para enfrentar as críticas dos pares, os mais aptos e mais dispostos a dirigirem aos concorrentes todas as armas específicas (lógicas e experimentais) que o campo lhes oferece. É a singularidade da competição regrada dos campos científicos que fomenta o desenvolvimento de mecanismos eficazes de universalização. O trabalho coletivo de confrontação crítica constrange os agentes, em sua dupla busca da verdade e do reconhecimento de sua competência, a comportarem-se racionalmente e sublimarem suas pulsões, possibilitando o avanço da reflexividade como resultado das ações de todos os agentes engajados no campo. É a lógica social do campo científico que fomenta a objetivação, pois não há realização individual da reflexividade que não possa ser direcionada por um concorrente contra seu autor, desviada contra ele como arma na disputa científica.

Nessa dinâmica, Bourdieu identifica a lógica da dominação simbólica, espécie de dominação que, nas sociedades diferenciadas, sobrepuja a dominação pela força física - o suporte material do exercício do poder -, conquistando sempre, em alguma medida, a legitimação do poder por parte daqueles que são por ele dominados, de modo que o reconhecimento radica no esquecimento da arbitrariedade original. Vê-se assim que o trabalho de esclarecimento histórico da gênese dos campos científicos pretende produzir meios teóricos e práticos para dominar os efeitos das constrições externas e internas que podem enfraquecer a capacidade de resistência à heteronomia: "é possível um pensamento sobre as condições sociais do pensamento que seja capaz de oferecer ao pensamento a possibilidade de uma verdadeira liberdade em relação a tais condições" (Bourdieu, 2007, p. 144).

A eficácia simbólica opera na medida em que encontra agentes dotados de uma aprendizagem prévia que os torna predispostos a reconhecê-la, ou seja, o habitus incorporado. Ela é, portanto, produzida pelas relações dinâmicas entre as características objetivas das organizações sociais e as disposições - resultado da socialização anterior - dos agentes que nelas atuam. Desse modo, a realidade exige uma dupla leitura sociológica, que abarque simultaneamente as estruturas objetivas dos diferentes mundos sociais que constituem o universo social (e seus mecanismos de reprodução e mudan- 
ça) e as estruturas de percepção e cognição - princípios de visão, divisão e classificação - mobilizadas no conhecimento prático desses mundos sociais estruturados segundo divisões objetivas. Os agentes constroem a realidade social, mas o fazem com os pontos de vista, os interesses e os princípios de visão condicionados por sua posição no mundo. Daí a importância fundamental do exame da gênese social das estruturas cognitivas, isto é, das condições históricas de sua produção no âmbito do principal sistema institucional moderno de socialização, os sistemas de ensino escolar, no topo dos quais estão as instituições de ensino superior e pesquisa que produzem conhecimento e formam produtores de conhecimento. Trata-se de investigar os processos de socialização que situam os mecanismos de produção, reprodução, mudança e luta por legitimação dos membros de diferentes classes e frações de classes sociais cujas ações produzem as mudanças em curso nas sociedades diferenciadas contemporâneas (cf. Bourdieu, 1997, 2004, 2008).

Com sua ênfase na autonomia relativa dos campos científicos, fundada na competição regrada por argumentos e evidências empíricas que constrange os agentes a comportarem-se racionalmente, reproduzindo as condições para o desenvolvimento de um interesse particular pelo universal, Bourdieu entende que sua descrição realista dessa lógica singular do campo científico poderia funcionar como uma "utopia razoável do que poderia ser um campo político em sintonia com a razão democrática” (2007, p. 154). Desse ponto de vista, a expansão das políticas de inovação de incentivo à produção de conhecimento comercial que, notadamente nos circuitos acadêmicos dos países europeus, promove a expansão do poder decisório dos administradores universitários e gestores de pesquisa, significa que a ciência está em perigo. A reprodução das condições sociais do desenvolvimento histórico da razão são ameaçadas por políticas científicas movidas por interesses econômicos, que injetam a heteronomia no interior dos campos científicos, comprometendo as possibilidades do avanço da reflexividade e da universalização: a ciência em perigo torna-se perigosa (cf. Bourdieu, 1997). É, portanto, no sentido de defesa da ciência, isto é, da manutenção das condições sociais que permitiram, na modernidade, a institucionalização desses universos de exceção capazes de fomentar perspectivas de conhecimento orientadas para a superação de particularismos que Bourdieu conclama os produtores de conhecimento, intelectuais e cientistas, a unirem-se em torno de seu interesse comum, isto é, a manutenção da lógica social de funcionamento dos campos capaz de fomentar um interesse particular pelo universal (cf. Bourdieu 1996, 1997, 2004). 


\section{Consideração FInal}

Ao colocar lado a lado o trabalho de articulação entre a epistemologia e a ética de Lacey e a contribuição de Bourdieu para uma sociologia do conhecimento e do poder busquei reter balizas fundamentais para a exploração das possibilidades das perspectivas histórico-racionalistas que buscam escapar da alternativa dualista entre o racionalismo ortodoxo e o relativismo. São possibilidades abertas por perspectivas transversais que buscam elucidar as relações entre diferentes esferas de atividades sem recusar-lhes suas especificidades, delineando problemas a serem investigados de modo a fazer avançar o pensamento reflexivo junto com o conhecimento empírico dos processos históricos de reprodução da organização social e dos valores culturais dominantes.

Limitando-me às confluências, é possível pensar, por exemplo, nas contribuições da sociologia histórica para o aprofundamento da compreensão das dinâmicas envolvidas nas etapas $\mathrm{M}_{2}$ e $\mathrm{M}_{4}$ da sistematização da atividade científica proposta por Lacey.

$\mathrm{Na}$ etapa $\mathrm{M}_{2}$, relativa ao empreendimento da pesquisa, é importante considerar a atuação das agências de fomento e das fundações filantrópicas que desempenham papel fundamental na história da difusão e implementação dos modelos científicos atualmente dominantes em variados campos disciplinares, contemplando desde os perfis institucionais desejáveis até as linhas de pesquisa a serem implementadas, notadamente entre os países periféricos aos centros de produção científica. Igualmente, é preciso examinar o papel que as encomendas de pesquisa, feitas principalmente pelas instituições econômicas, vêm desempenhando na dinâmica geral das instituições e dos grupos de pesquisa.

Quanto à etapa $\mathrm{M}_{4}$, que concerne à disseminação dos resultados científicos, é possível considerar uma miríade de instituições, distribuídas em numerosas esferas de atividade social, envolvidas em diferentes circuitos de comunicação que se estendem da comunicação propriamente científica entre os produtores de conhecimento nos periódicos especializados e congressos internacionais à divulgação científica nos meios de comunicação de massa, da grande imprensa às telecomunicações. Em especial a pesquisa sobre esse segundo tipo de circuito de comunicação pode contribuir para o esclarecimento dos processos culturais de ampla difusão dos valores do progresso tecnológico e da visão das potencialidades infinitas do conhecimento instrumental, correlata à percepção de que não existem outros modos de conhecimento disponíveis.

No que se refere à perspectiva do pluralismo estratégico proposto por Lacey, pode ser promissor considerar a elaboração de Terry Shinn (2008), a partir da sociologia de Bourdieu, dos regimes de produção e difusão de ciência e tecnologia. Cada regime corresponde, em sua origem, a um ambiente cognitivo, político e econômico específico 
de certa época e seu funcionamento define formas particulares de treinamento e certificação, de modos de trabalho e de divisão do trabalho, de critérios de validação e sistema de recompensas, de trajetórias profissionais, de modalidades de produtos, de forma e extensão dos mercados, de sistema de circulação entre produção e mercado. Com base na discriminação desse complexo conjunto de fatores, Shinn descreve uma história pluralista da ciência moderna, na contracorrente da visão homogeneizante de uma única organização possível para a prática científica, podendo fornecer elementos importantes para a especificação das condições de realização do pluralismo estratégico no contexto da ciência contemporânea.

Tratam-se apenas de alguns exemplos indicativos das possibilidades de diálogo entre perspectivas transversais que têm contribuído significativamente para o entendimento das relações entre a ciência e a sociedade sem reduzir uma à outra, mas tampouco se abstendo de decifrar as forças sociais que atuam para a manutenção da unilateridade do desenvolvimento da razão, em uma época em que as consequências da adoção das aplicações tecnológicas do conhecimento instrumental desafiam a capacidade de controle humano sobre o mundo, seja enquanto natureza, seja enquanto cultura.(

\section{Sylvia Gemignani Garcia Departamento de Sociologia,}

Faculdade de Filosofia, Letras e Ciências Humanas, Universidade de São Paulo, Brasil. sylgemig@usp.br 


\title{
On social obstacles to the historical development of reason
}

\begin{abstract}
After characterizing the modern problem of the limits and possibilities of scientific reason, as it is formulated in 19th century sociology, I clarify the question of the duality of instrumental knowledge, which informs technical control of the world, and reflexive knowledge, which encompasses the various dimensions of meaning in human practices. Then, I expound two exemplary explanations, proposed by reflexive perspectives, for the contemporary predominance of instrumental knowledge: the model of interaction between values and scientific activities proposed by Hugh Lacey; and Pierre Boudieu's sociology of the social conditions for the development of scientific fields. By putting side by side a philosophical work articulating connections between epistemology and ethics, and a sociological theory about the social conditions of the historical development of reason, I introduce fundamental markers for exploring the possibilities of historical rationalist perspectives that try to avoid the dualistic alternative of orthodox rationalism and relativism. Both analyses explore the possibilities opened by transversal perspectives that try to elucidate the relations between different spheres of activity, without ignoring their particularities, delineating problems to be investigated in a way that furthers reflexivity together with empirical knowledge of the historical processes of reproduction of social organization and of the dominant values.
\end{abstract}

KEYwORDS • Modern society. Instrumental knowledge. Reflexive knowledge. Scientific practices. Research strategies. Scientific field. H. Lacey. P. Bourdieu.

\section{REFERÊNCIAS BIBLIOGRÁfICAS}

BARnes, B. et al. Estudios sobre sociologia de la ciencia. Madrid: Alianza, 1980.

Вонме, G. \& Sтенк, N. The knowledge society. Dordrecht: Reidel, 1986.

Bourdieu, P. A economia das trocas simbólicas. Tradução S. Miceli. São Paulo: Perspectiva, 1974.

. Esboço de uma teoria da prática. In: Ortiz, R. (Org.). Pierre Bourdieu. São PauloÁtica, 1983. p. 4681.

. As regras da arte. Tradução M. L. Machado. São Paulo: Companhia das Letras, 1996.

. Les usages sociaux de la science. Paris: INRA, 1997.

. Para uma sociologia da ciência. Lisboa: Edições 70, 2004.

. O poder simbólico. Tradução F. Tomaz. Rio de Janeiro: Bertrand Brasil, 2005.

Meditações pascalianas. Tradução S. Miceli. Rio de Janeiro: Bertrand Brasil, 2007.

A distinção: crítica social do julgamento. São Paulo/Porto Alegre: Edusp/Zouk, 2008.

Dupas, G. (Ed.). Tensões entre meio-ambiente e crescimento econômico. São Paulo: Editora Unesp, 2008.

Durkheim, É. Educação e sociologia. 8. ed. São Paulo: Melhoramentos, 1972. A evolução pedagógica. Porto Alegre: Artes Médicas, 1995.

O suicídio: estudo sociológico. Tradução L. Cary \& M. Stahel. São Paulo: Martins Fontes, 2004.

Eтzкошітz, H. The future of university and the university of the future: evolution of ivory tower to entrepreneurial paradigm. Research Policy, 29, 2, p. 313-30, 2000.

Etzkowitz, H. \& LeydesdorfF, L. The dynamics of innovation: from national systems and 'mode 2' to a triple helix of university-industry-government relations. Research Policy, 29, 2, p. 109-19, 2000.

Gibbons, M. et alli. The new production of knowledge. London: Sage, 1999. 
LAcey, H. A controvérsia sobre os transgênicos: questões científicas e éticas. São Paulo: Ideias e Letras, 2006. .Valores e atividade científica 1. São Paulo: Associação Filosófica Scientiae Studia/Editora 34, 2008a. . Crescimento econômico, meio-ambiente e sustentabilidade social: a responsabilideade dos cientistas e a questão dos transgênicos. In: Dupas, G. (Ed.). Tensões entre meio-ambiente e crescimento econômico. São Paulo: Editora Unesp, 2008b. p. 91-130.

. O lugar da ciência no mundo dos valores e da experiência humana. Scientiae Studia, 7, 4, p. 681701,2009 .

. Valores e atividade científica 2. São Paulo: Associação Filosófica Scientiae Studia/Editora 34, 2010.

. Tecnociência comercialmente orientada ou investigação multiestratégica? Scientiae Studia, 12, 4, p. 669-95, 2014.

"Holding" and "endorsing" claims in the course of scientific activities. Studies in History and Philosophy of Science. No prelo.

LaGey, H. \& Mariconda, P. R. O modelo das interações entre as atividades científicas e os valores. Scientiae Studia, 12, 4, p. 64,3-68, 2014.

Le Breton, D. Adeus ao corpo. $3^{\text {a }}$ ed. Campinas: Papirus, 2008.

Lundvall, B.-A. The social dimension of the learning economy. DRUID Working Papers, 96-1, Apr., 1996.

Marcovich, A. \& Shinn, T. Posfácio. Robert K. Merton, fundador da sociologia da ciência: comentários, insights, críticas. In:___ \& __. (Org.). Robert K. Merton. Ensaios de sociologia de ciência. São Paulo: Associação Filosófica Scientiae Studia/Editora 34, 2013. p. 253-72.

Marcovich, A. \& Shinn, T. (Org.). Robert K. Merton. Ensaios de sociologia de ciência. São Paulo: Associação Filosófica Scientiae Studia/Editora 34, 2013.

Mariconda, P. R. Technological risks, transgenic agriculture and alternatives. Scientiae Studia, 12, special issue, p. 75-104, 2014.

Marx, K. \& Engels, F. The German ideology. Moscow: International Publishers, 1970.

Mauss, M. Sociologia e antropologia. Tradução P. Neves. São Paulo: Cosac Naify, 2003.

Orтіz, R. (Org.). Pierre Bourdieu. São Paulo: Ática, 1983.

Reich, R. B. O trabalho das nações. Tradução G. Fullmann. São Paulo: Educator, 1994.

SACrini, M. Mundo da vida e racionalidade científica. Scientiae Studia, 12, 4, p. 679-710, 2014.

Simmel, G. As grandes cidades e a vida do espírito. Tradução L. Waizbort. Mana, 11, 2, p. 577-91, 2005.

Shinn, T. Regimes de produção e difusão da ciência: rumo a uma organização transversal do conhecimento. Scientiae Studia, 6, 1, p. 11-42, 2008.

Shinn, T. \& Ragouet, P. Controvérsias sobre a ciência. São Paulo: Scientiae Studia/34, 2008.

WEBER, M. A ciência como vocação. In: Ciência e política: duas vocações. Tradução L. Hegenberg e O. S. da Mota. São Paulo: Cultrix, 1970 [1919]. p. 1552.

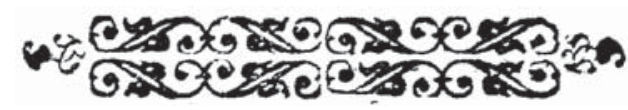

